\title{
Reply to correspondence letter by S. Bertelloni et al. Adolescent medicine in Europe: integration and cooperation are needed
}

\author{
Oya Ercan • Mujgan Alikasifoglu • Mehmet Vural
}

Received: 1 October 2008 /Accepted: 1 October 2008 / Published online: 21 October 2008

(C) Springer-Verlag 2008

We would like to thank Bertelloni et al. for their comments on our study concerning adolescent health care delivery and training in Europe [1]. Although we propose the integration of an adolescent health care program into primary health care systems, we agree with Bertelloni et al. that secondary care needs to be given in the pediatric departments with a multidisciplinary approach. Besides, as we had stated in our study, adolescent medicine needs to be a certified multidisciplinary subspecialty of pediatrics. Consequently, the training of physicians who will give primary care to adolescents could be organized by pediatricians. Confidentiality, as a main issue in adolescent health care, could be implemented in every European country who undertakes the obligations of United Nations Convention on the rights of the child through appropriate legal changes produced by the pressure of international pediatric communities advocating for children. Meetings, such as that mentioned by

O. Ercan · M. Alikasifoglu

Divisions of Adolescent Medicine and Endocrinology,

Department of Pediatrics, Cerrahpasa Medical Faculty, Istanbul University,

Istanbul, Turkey

M. Vural $(\bowtie)$

Department of Pediatrics, Cerrahpasa Medical Faculty, Istanbul University,

Istanbul, Turkey

e-mail: vuralm@istanbul.edu.tr
Bertelloni et al., may contribute to these efforts. Regarding the training, mentioned societies and chapters certainly provided valuable contributions in continuing medical education for adolescent medicine. However, EuTEACH (http://www.euteach.com/) has proven to be a guide for trainees-teaching professionals with its comprehensive curriculum for adolescent health professionals and was found to be useful by the trainees [2]. We think that adolescent health care delivery and training will be improved with different means and different techniques in each European country. Although we are aware that the same strategies may not be appropriate for all European countries with different health care systems and different economical status, we hope that some considerable changes will be achieved during the coming years. Our study gives the picture of the actual situation in the continental Europe and it will be interesting to see the evolution in $4-5$ years.

\section{References}

1. Ercan O, Alikasifoglu M, Erginoz E, Janda J, Kabicek P, Rubino A, Constantopoulos A, Ilter O, Vural M (2008) Demography of adolescent health care delivery and training in Europe. Eur J Pediatr Jul 2 [Epub ahead of print]. doi:10.1007/s00431-008-0759-1

2. Michaud PA, Stronski S, Fonseca H, Macfarlane A, EuTEACH Working Group (2004) The development and pilot-testing of a training curriculum in adolescent medicine and health. J Adolesc Health 35:51-57 